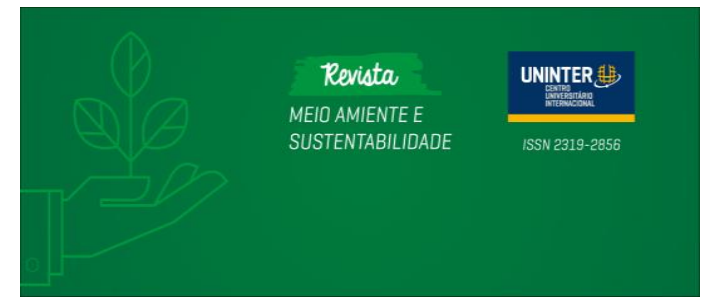

Revista Meio Ambiente e Sustentabilidade

Versão on-line ISSN 2319-2856

Volume 17, número 8. Curitiba - PR. jul/dez - 2019

\title{
Por uma sociologia do desenvolvimento sustentável: uma reflexão sobre a criação de um novo campo disciplinar
}

\section{Diogo Guedes Vidal}

Mestrado em Sociologia pela Faculdade de Letras da Universidade do Porto, Portugal(2016) Pesquisador da FP-ENAS / Universidade Fernando Pessoa, Portugal

\section{RESUMO}

O presente ensaio reflete a oportunidade de desenvolver um campo disciplinar da sociologia orientado para a problemática do desenvolvimento sustentável e apoiado na interdependência dos 17 objetivos para o desenvolvimento sustentável da Agenda 2030 das Nações Unidas. A partir de um exercício de reflexão em torno das conquistas científicas da sociologia nas suas mais diversas áreas, evidenciase a necessidade de reunir estes saberes e de interpretar e analisar este novo paradigma à luz de uma mudança social que se pretende implementar. Sem pretensões de impor a criação de um novo campo disciplinar, propõe-se antes um exercício de reflexão e imaginação sociológica.

Palavras-chave: Desenvolvimento sustentável; Sociologia; Interdisciplinaridade; Mudança social 


\title{
For a sustainable development sociology: a reflection on the creation of a new disciplinary field
}

\section{Por una sociología del desarrollo sostenible: una reflexión sobre un nuevo campo disciplinar}

\begin{abstract}
This essays aims to reflect about the opportunity to develop a disciplinary field of sociology with the focus on the sustainable development issue, drawing on the interdependent of the seventeen sustainable development goals of 2030 Agenda. An exercise is made based on the presentation of the main scientific achievements of sociology in its most diverse areas, putting in evidence the urgent need to gather these types of knowledge and to interpret and analyze this new paradigm in the light of a social rupture that is intended to be implemented. Without pretensions to impose the creation of a new disciplinary field, it proposes an exercise of reflection and sociological imagination.
\end{abstract}

Keywords: Sustainable development; Sociology; Interdisciplinarity; Social change

RESUMEN

El presente ensayo estudia la posibilidad de desarrollar un nuevo campo disciplinar de la sociología, orientado a la problemática del desarrollo sostenible y apoyado en la interdependencia de los 17 objetivos para el desarrollo sostenible de la Agenda 2030 de las Naciones Unidas. A partir de un ejercicio de reflexión acerca de las conquistas científicas de la sociología en sus más diversas áreas, se evidencia la urgencia de unir esos saberes, de interpretar y analizar ese nuevo paradigma a la luz del cambio social que se pretende lograr. Sin la pretensión de imponer la creación de un nuevo campo disciplinar, se propone un ejercicio de reflexión e imaginación sociológica.

Palabras-clave: Desarrollo sostenible; Sociología; Interdisciplinaridad; Cambio social

\section{INTRODUÇÃO}

O Desenvolvimento Sustentável faz agora parte de quase todos os discursos e agendas políticas e internacionais. Relativamente recente, aponta-se que o conceito tenha emergido nos anos 70 do século XX, inicialmente sobre a lógica de um "Eco Desenvolvimento" que debatia a relação complexa entre o crescimento econômico e o ambiente(SACHS, 2000). Contudo, é com o Relatório Brundtland que se eterniza o conceito de Desenvolvimento Sustentável como um equilíbrio entre as dimensões econômica, ambiental e social, tendo presente que o desequilíbrio de uma das partes enfraquece as demais (BRUNDTLAND, 1987).

São diversos os campos da ciência e do conhecimento, dentro da academia, que se têm debruçado sobre a importância de mudar paradigmas. Esta mudança de paradigma dota o indivíduo, enquanto ser humano habitante do planeta, do papel de protagonista e, simultaneamente, alvo dessa mesma mudança. Mesmo fora da academia, a sociedade civil, 
políticos e os grupos ativistas têm sido chamados a debater sobre este conceito, mais concretamente no que se refere às medidas e políticas necessárias para optar pelo caminho de um desenvolvimento digno e sustentável. A sociedade não é, nem deve, ser indiferente à esta nova realidade e, por isso, importa cada vez mais aprofundar estas questões, discutir os seus impactos para que, no fim, a decisão seja consciente e, sobretudo, sensata (SCHMIDT et al., 2016).

Longe vai o tempo em que a Sociologia, e a ciência em geral, se assumiam como saberes estanques, intransponíveis e incomunicáveis com as demais ciências. Talvez nunca o tenha sido, mas os seus campos de atuação e as suas ramificações têm vindo a diversificar-se dada a complexidade da sociedade que assim o exige. O objetivo deste ensaio é propor um exercício de reflexão sobre a possibilidade de se criar um campo da sociologia direcionado para as questões do desenvolvimento sustentável que assente, na sua essência, na necessidade em desenvolver um olhar crítico e reflexivo sobre as implicações da implementação deste paradigma que, inevitavelmente, acarretará um conjunto de mudanças significativas no mundo contemporâneo. A grande questão que se coloca, e que se procura tentar responder, é se no meio desta oportunidade, em que a agenda midiática, os projetos de doutorado e a sociedade civil estão voltados para esta linha de pensamento, existe espaço para a possibilidade de desenvolvimento deste campo disciplinar da sociologia.

Trata-se de conjugar esforços teórico-metodológicos, provindos da sociologia e não só, em que os objetos sejam os comportamentos, as ações, as atitudes e as vontades voltados, ou não, para uma problematização do desenvolvimento sustentável numa vertente multidisciplinar. O que não deve ser esquecido, e talvez seja esta uma das duas grandes potencialidades dos Objetivos para o Desenvolvimento Sustentável da Agenda 2030 (ODS), é que os mesmos traduzem a mensagem que "there is no one-size-fits-all", ou seja, a solução não é única e os caminhos para um modo de vida e crescimento sustentável, para um desenvolvimento humano, devem ser ajustados à realidade social, política e econômica de cada cultura, espaço ou sociedade. Preconizam ainda, e sendo esta a segunda grande potencialidade dos mesmos, o mote "no one left behind", no sentido de que o desenvolvimento sustentável é um caminho a percorrer por todos, implicando um envolvimento geral, ainda que utópico ou de difícil concretização, que deve ser, pelo menos, tentado. 


\section{BREVES NOTAS SOBRE UMA POSSIBILIDADE}

Desde os seus primórdios que a Sociologia tem particular interesse por desconstruir as dinâmicas sociais para, em seguida, reconstruí-las de modo a torná-las um objeto sociológico. Fruto de convulsões sociais e dos questionamentos da forma como as sociedades se encontram organizadas, a Sociologia enquanto ciência ganha relevo na Revolução Francesa de 1789 e galga caminho até à Revolução Industrial do século XVIII e XIX. O que estes dois acontecimentos têm em comum é o fato de simbolizaram, como todos sabemos, uma ruptura de paradigma, ou seja, uma mudança na forma da organização social da sociedade em termos políticos, sociais e econômicos. A linha que a sociologia percorreu e os contribuições que deu no âmbito das lutas de classe, dos estudos de gênero e feministas, no campo dos estudos urbanos e rurais, no desenvolvimento de uma sociologia da cultura, do ambiente, da educação, do trabalho e das organizações solidificam-na enquanto ciência com método e rigor aplicado ao objeto de estudo. $\mathrm{O}$ Desenvolvimento Sustentável também é, ele próprio, um movimento de ruptura que, a curto, médio e longo de prazo estará, ou espera-se que esteja, incorporado. E porque não encarar enquanto tal? O que o mesmo preconiza é que o desenvolvimento deve ocorrer para que todos os indivíduos possam satisfazer as suas necessidades sem comprometer que as gerações futuras satisfaçam as suas. Promove a interdependência entre as dimensões social, econômica e ambiental em prol de uma justiça social para todos e de todos, com benefícios iguais e distribuídos de forma equitativa. E se assim o é, então desde logo percebemos que a Sociologia pode e deve ter aqui um papel primordial.

Os longos debates têm procurado sair da esfera unicamente ambiental para outras como a questão do emprego digno, do acesso a saúde (OLIVEIRA et al., 2019; VIDAL et al., 2018) e educação de qualidade, do desenvolvimento de energias renováveis, da mitigação e adaptação às alterações climáticas (GUERRA et al., 2017) e, entre outras, da própria sustentabilidade urbana (OLIVEIRA; VIDAL; FERRAZ, 2019; VIDAL et al., 2019). Exemplo disto são o que os 17 ODS postulam e que procuram, primeiro, colocar a tônica nos pontos nevrálgicos que precisam de soluções a curto prazo e, segundo, demonstrar a sua interdependência. Trata-se, por isso, de ter consciência que em uma sociedade desigualitária o desenvolvimento sustentável não prospera, ficando pelo caminho (NATIONAL ACADEMIES OF SCIENCES, ENGINEERING, 2016). Além disto, o 
desenvolvimento sustentável pleno só se alcança quando todos os objetivos estiverem concretizados(COSTA, 2012); pois, a erradicação da fome em todas as suas dimensões, o combate das desigualdades globais, a preservação e manutenção do planeta e o desenvolvimento de uma economia inclusiva são interdependentes (UNITED NATIONS, 2015). Este desenvolvimento funciona como um todo, interligado, um verdadeiro facto social que Durkheim tão longinquamente preconizou e que continua a ter aplicabilidade no mundo actual (DURKHEIM, 2002).

Ainda nesta linha, as teorias feministas continuam a ser importantes quando no século XXI são ainda gritantes as disparidades salariais de gênero (BONIOL et al., 2019). As correntes Marxistas têm aplicabilidade em uma sociedade onde o fosso entre os mais ricos e pobres se agiganta (MARX, 2017). As teorias de Celso Furtado da Sociologia do Desenvolvimento encontram lugar em um exacerbar das diferenças entre os países desenvolvidos e em desenvolvimento (FURTADO, 2009). As teorias da sociologia da educação e da saúde continuam a demonstrar que nem todos temos acesso aos mesmos serviços de qualidade, pois a expectativa de vida e as possibilidades de ação no campo social não são as mesmas para todos. A Sociologia do Consumo de Bauman (BAUMAN, 2000) é contemporânea aos princípios basilares do próprio desenvolvimento sustentável.

O Novo Paradigma Ecológico (NEP) de Catton e Dunlap continua a fazer sentido na batalha pela conscientização da degradação ambiental e o agravamento das alterações climáticas com impactos diretos na saúde ambiental e pública (BARREIRA et al., 2018; CATTON; DUNLAP, 1978; VIDAL, 2018). Catton e Dunlap (1978) reconheceram a interação entre o ambiente físico, a organização social e o comportamento humano pela dependência dos ecossistemas das sociedades humanas. Foram das primeiras vozes no campo sociológico a referir um ecocentrismo para denotar um sistema de valores centrado na natureza, em oposição a um centrado no homem (antropocêntrico). O NEP preconiza, também, vários pressupostos que parecem estar alinhados com os principais fios orientadores da sustentabilidade: a supremacia do ser humano perde expressão quando tomamos consciência de que o mesmo faz parte de um conjunto muito diversificado de espécies que convivem, de forma interdependente, com ele (CATTON; DUNLAP, 1980); as ações do homem têm impacto direto no meio ambiente, social e cultural que o rodeia; o homem, enquanto ser que habita o planeta, depende do meio ambiente, limitado e em risco, o que coloca em evidência a sua dependência e fragilidade perante o mesmo; e, por 
fim, mas não menos importante, a consciência de que o desenvolvimento tecnológico do qual o homem foi o grande promotor, principalmente no século XX, não deve deixar de ser balizado pelos limites não extensíveis do planeta. A propósito deste último ponto, e ainda que muito ligado à dimensão ambiental mas não só, o século passado é espelho de grandes contradições que nos trouxeram até à situação atual: se por um lado os avanços na ciência e tecnologia foram determinantes para a melhoria da qualidade de vida, por outro foram destruidores enquanto ferramentas para a ocorrência de guerras, conflitos sociais e aprofundamento de disparidades entre e dentro de países (OLIVEIRA; ARCHER, 2015; SCHMIDT, 1999). Nesta linha de pensamento, a obra de Hobsbawm (1995) "A Era dos extremos: o breve século XX (1914-1991)" é paradigmática sobre esta questão referindo, de forma bastante explícita, que a forma como os avanços em prol do bem da humanidade foram geridos resultou numa capacidade de autodestruição dos recursos naturais tendo como justificativa a satisfação das necessidades de uma sociedade em forte expansão.

É por este motivo, principalmente, que os ODS (Tabela 1), herdeiros dos Objetivos do Milênio, foram traçados e desenvolvidos, com grau de detalhe e, até mesmo, assertividade na prossecução dos mesmos. A Agenda 2030 resultou da reunião que juntou 198 estados membros das Nações Unidas e a sociedade civil a 25 de setembro de 2015. Foi aí que se efetivou um acordo intergovernamental mas, sobretudo, intergeracional, inicialmente desenvolvido na Conferência Rio+20 realizada em 2012. Beck(1986) coloca a tônica exatamente nas ações do homem como origem e consequência da degradação ambiental e social que constatámos e, nesta linha, a ponte com a Sociedade de Risco de Giddens assenta na preocupação com um futuro incerto e, de certa forma, inseguro (GIDDENS, 1990).

Tabela 1 - 17 Objetivos para o Desenvolvimento Sustentável da Agenda 2030 da Nações Unidas

1. Acabar com a pobreza em todas as suas formas, em todos os lugares.

2. Acabar com a fome, alcançar a segurança alimentar e melhoria da nutrição e promover a agricultura sustentável.

3. Assegurar uma vida saudável e promover o bem-estar para todos, em todas as idades.

4. Assegurar a educação inclusiva, equitativa e de qualidade, e promover oportunidades de aprendizagem ao longo da vida para todos.

5. Alcançar a igualdade de gênero e empoderar todas as mulheres e meninas. 
6. Assegurar a disponibilidade e gestão sustentável da água e saneamento para todos.

7. Assegurar o acesso confiável, sustentável, moderno e a preço acessível à energia para todos.

8. Promover o crescimento econômico sustentado, inclusivo e sustentável, emprego pleno e produtivo e trabalho decente para todos.

9. Construir infraestruturas resilientes, promover a industrialização inclusiva e sustentável e fomentar a inovação.

10. Reduzir a desigualdade dentro dos países e entre eles.

11. Tornar as cidades e os assentamentos humanos inclusivos, seguros, resilientes e sustentáveis.

12. Assegurar padrões de produção e de consumo sustentáveis.

13. Tomar medidas urgentes para combater a mudança climática e seus impactos.

14. Conservação e uso sustentável dos oceanos, dos mares e dos recursos marinhos para o desenvolvimento sustentável.

15. Proteger, recuperar e promover o uso sustentável dos ecossistemas terrestres, gerir de forma sustentável as florestas, combater a desertificação, deter e reverter a degradação da terra e deter a perda de biodiversidade.

16. Promover sociedades pacíficas e inclusivas para o desenvolvimento sustentável, proporcionar o acesso à justiça para todos e construir instituições eficazes, responsáveis e inclusivas em todos os níveis.

17. Fortalecer os meios de implementação e revitalizar a parceria global para o desenvolvimento sustentável.

Fonte: (UNITED NATIONS, 2015)

Ao nos depararmos com a complexidade dos objetivos acima identificados compreendemos os desafios com os quais a Sociologia, na sua vertente científica e pública, se depara e deparará (BURAWOY, 2009). É evidente que já existe um trabalho consolidado em múltiplas dimensões que estes objetivos, ambiciosos, tocam mas falta um esforço integrado e coordenado dos vários saberes acumulados, inquestionavelmente necessários para lidar com a ruptura que se pretende em prol de uma sociedade mais equitativa, digna e sustentável. Talvez possamos descartar a palavra sustentável pois, na verdade, se uma sociedade for justa e igualitária a sustentabilidade está implícita no seu DNA social. Uma debilidade destes pressupostos reside no fato do mesmos serem, em muitas situações, utilizados de forma "vazia", ou seja, sem sentido ou aplicabilidade. Melhor dizendo, carecem, à sua apresentação, medidas concretas de aplicação, capazes de lhes dar resposta. Se olharmos para dentro do corpo teórico-metodológico da Sociologia, quando 
delineamos objetivos é necessário estipular formas de os conseguir atingir, ou seja, de responder, primeiro, à questão que conduz a nossa investigação e, segundo, ir de encontro aos objetivos inicialmente traçados. Ora, é também neste domínio que o rigor metodológico e conceptual, a que a investigação sociológica obriga, pode dar um importante contributo na implementação dos ODS: diagnosticar as especificidades de cada realidade que será objecto de intervenção, pois dentro de um território existem múltiplos territórios e múltiplas realidades que diferem entre si e que, por isso, implicam um distanciamento de olhares únicos ou universais; delinear as ações necessárias em prol da mudança pretendida; capacitar as populações, envolve-las no processo e sensibilizá-las para a mudança; e, por fim, acompanhar o procedimento que, numa lógica correta de “Desenvolvimento”, será um fim em aberto, contínuo e em constante modificação.

Ainda na linha dos desafios que a Sociologia enfrenta no desenvolvimento de um corpo teórico capaz de dar resposta ao Desenvolvimento Sustentável, encontramos vozes que entendem que a Sustentabilidade e todas as movimentações em seu redor escondem um capitalismo disfarçado, "verde", que se procura esconder por debaixo do véu da igualdade e da dignidade em prol de ver conquistados valores puramente ideológicos, políticos e econômicos (DIAS; GLAUCO RIBEIRO TOSTES, 2009). Não deixa de ser verdade, mas se entendermos cada fenômeno unicamente por um único prisma, podemos cair no erro de perdermos a capacidade de olhar de forma crítica e reflexiva para o problema, características a que a Sociologia nos tem habituado.

\section{CONCLUSÃO}

Por fim, pretendeu-se abrir espaço para refletir sobre a possibilidade de desenvolver um campo para uma Sociologia do Desenvolvimento Sustentável, capaz de responder aos desafios complexos que se colocam. Procura-se, no fundo, reunir esforços e pontos convergentes em prol do mesmo objetivo que é o de contribuir para uma sociedade mais justa e igualitária, sustentável e integradora. Os grandes desafios sociais ganham cada vez maior expressão, fruto da globalização e do fluxo de bens, serviços e pessoas, em lugares atemporais e de difícil definição. A sociologia é capaz de responder, mas talvez valesse a pena olhar para a oportunidade como uma possibilidade. 


\section{AGRADECIMENTOS}

Este trabalho contou com o apoio da FP-ENAS, Unidade de Investigação UFP em Energia, Ambiente e Saúde financiada pela FCT - Fundação para a Ciência e a Tecnologia, I.P. através do projecto UID/MULTI/4546/2019.

\section{REFERÊNCIAS BIBLIOGRÁFICAS}

BARREIRA, E. et al. Cancro do Pulmão e Poluição: um estudo transversal. Onco.News, n. 37, p. 14-19, 2018.

BAUMAN, Z. Liquid modernity. Oxford: Polity Press, 2000.

BECK, U. Risk society. Towards a new modernity. London: SAGE, 1986.

BONIOL, M. et al. Gender equity in the health workforce: Analysis of 104 countries. Geneva: World Health Organization, 2019.

BRUNDTLAND, G. H. Our Common Future-Call for Action. Environmental Conservation, v. 14, n. 4, p. 291-294, 1987.

BURAWOY, M. The public sociology wars. In: JEFFRIES, V. (Ed.). . Handbook of public sociology. Maryland: Rowman \& Littlefield Publishers, 2009. p. 449-473.

CATTON, W. R.; DUNLAP, R. E. Environmental Sociology: a New Paradigm. The American Sociologist, v. 13, n. February, p. 41-49, 1978.

CATTON, W. R.; DUNLAP, R. E. A new ecological paradigm for post-exuberant sociology. American Behavioral Scientist, v. 24, n. 1, p. 45-47, 1980.

COSTA, A. F. Desigualdades sociais contemporâneas. Lisboa: Mundos Sociais, 2012.

DIAS, G.; GLAUCO RIBEIRO TOSTES, J. Desenvolvimento sustentável: do ecodesenvolvimento ao capitalismo verde. Revista da Sociedade Brasileira de Geografia, v. 2, 2009.

DURKHEIM, É. As regras do método sociológico. 17. ed. São Paulo: Companhia Editora Nacional, 2002.

FURTADO, C. Desenvolvimento e subdesenvolvimento. Rio de Janeiro: Centro Celso Furtado / Contraponto, 2009.

GIDDENS, A. As consequencias da modernidade. Sao Paulo: Editora da UNESP, 1990. 
GUERRA, J. et al. CLIMADAPT.LOCAL - RESULTADOS PRELIMINARES DE UM INQUÉRITO ALARGADO. Portugal, território de territórios. Atas do IX Congresso Português de Sociologia. Anais...Lisboa: Associação Portuguesa de Sociologia, 2017Disponível em: http://repositorio.ul.pt/handle/10451/27900?mode=full

HOBSBAWM, E. Era dos extremos: o breve século XX (1914-1991). São Paulo: Companhia das Letras, 1995.

MARX, K. O capital. Lisboa: Edições 70, 2017.

NATIONAL ACADEMIES OF SCIENCES, ENGINEERING, AND M. Pathways to urban sustainability: challenges and opportunities for the United States. Washington, DC: The National Academies Press, 2016. Disponível em: <https://www.nap.edu/catalog/23551/pathways-to-urban-sustainability-challenges-andopportunities-for-the-united $>$.

OLIVEIRA, G. M. et al. Measuring Health Vulnerability: An Interdisciplinary Indicator Applied to Mainland Portugal. International Journal of Environmental Research and Public Health, v. 16, n. 21, p. 1-18, 2019.

OLIVEIRA, G. M.; ARCHER, A. B. Ambiente e Desenvolvimento Sustentável: Educação para a Ética e Cidadania. Sensos 10 - Revista do Centro de Investigação e Inovação em Educação, v. 5, n. 2, p. 185-200, 2015.

OLIVEIRA, G. M.; VIDAL, D. G.; FERRAZ, M. P. Urban Lifestyles and Consumption Patterns. In: LEAL FILHO, W. et al. (Eds.). . Sustainable cities and communities. Encyclopedia of the UN sustainable development goals. Cham: Springer Nature Switzerland AG, 2019. p. 1-10.

SACHS, J. D. Desenvolvimento como liberdade. Sao Paulo: Companhia das Letras, 2000.

SCHMIDT, L. Sociologia do ambiente: genealogia de uma dupla emergência. v. XXXIV, n. 150, p. 175-210, 1999.

SCHMIDT, L. et al. Primeiro grande inquérito sobre sustentabilidade - relatório final. Lisboa: [s.n.]. Disponível em: $<$ https://www.sonae.pt/fotos/editor2/inq_sustentabilidade_pp_31agosto2016_final_3_.pd $f>$.

UNITED NATIONS. Transforming our world: The 2030 Agenda for Sustainable Development. Resolution adopted by the General Assembly on 25 September 2015, A/RES/70/1. Geneva: [s.n.]. Disponível em: <http://www.un.org/en/development/desa/population/migration/generalassembly/docs/gl obalcompact/A_RES_70_1_E.pdf>.

VIDAL, D. G. et al. Differential Mortality and Inequalities in Health Services Access in Mainland Portugal. Finisterra - Revista Portuguesa de Geografia, v. 53, n. 109, p. 53-70, 2018. 
VIDAL, D. G. Ecoconsciencialização das cidades: uma emergência global. Plataforma Barómetro Social, n. 2, 2018.

VIDAL, D. G. et al. Cities Challenges in the Contemporary Societies: Urban Sustainability and Environmental Issues. SOCIOLOGIA ON LINE, Revista da Associação Portuguesa de Sociologia (APS), v. 20, p. 119-138, 2019. 